\title{
BETWEEN SYMBOLISM AND METAPHOR
}

\author{
Saulius GECAS \\ Studio WOA (workshop of open architecture), Via Ancona N.21 sc.A, int. 10, C.A.P. 00198 Rome, Italy \\ E-mail: sauliusgecas@hotmail.com
}

Received 18 September 2014; accepted 15 December 2014

\begin{abstract}
The article provides a discussion of symbolic aspects and uses of metaphors in Massimiliano Fuksas architecture. Despite of the fact that his architectural projects are very different they are sculptural and abstract leading to ambiguous reflections. The author argues that each architectural project of Massimiliano Fuksas can be related to certain metaphors and level of symbolisation. His metaphors are often metaphors for our feelings, they are emotionally understandable and yet not so easy to name. The article is an attempt to expose and analyze them.
\end{abstract}

Keywords: Massimiliano Fuksas, modernism, symbols, Le Corbusier.

Symbolism - the art or practice of using symbols especially by investing things with a symbolic meaning or by expressing the invisible or intangible by means of visible or sensuous representations: as

$a$ : artistic imitation or invention that is a method of revealing or suggesting immaterial, ideal, or otherwise intangible truth or states

$b$ : the use of conventional or traditional signs in the representation of divine beings and spirits

Metaphor - a word or phrase for one thing that is used to refer to another thing in order to show or suggest that they are similar, an object, activity, or idea that is used as a symbol of something else.

Webster's Dictionary

\section{Introduction}

In the book "Towards a new architecture" Le Corbusier wrote:

"The Architect, by his arrangement of forms, realizes an order which is a pure creation of his spirit; by forms and shapes he affects our senses to an acute degree and provokes plastic emotions; by the relationships which he creates he wakes profound echoes in us, he gives us the measure of an order we feel to be in accordance with that of our world, he determines the various movements of our heart and of our understanding; it is then that we experience the sense of beauty" (Le Corbusier 1986: 1).

Can something better be said about an Architects work?

It was said by Le Corbusier - one of the brightest and most active pioneers of modern architecture. No matter how much avant-garde or technologically progressive architecture may be or how revolutionarily moving away from traditional aesthetical values of the past; the words "spirit, emotions, heart and beauty" have and always will be an architect's essential qualities of excellence and creativity.

Although the great Le Corbusier never directly wrote about metaphors and symbolism he basically alluded to deep spiritual emotions caused by the architects designed forms and shapes, which reflect in our personal subconscious universe, which is essentially a world of metaphors and symbols.

It is virtually impossible to trace when and how symbolism and metaphors emerged in the architectural language. Perhaps symbols and metaphors in architecture appeared from the first steps of man's creativity, when he "designed" his first shelter, cut down or left existing openings as the doors, or selected the location of the fire place inside his living space. 
Nevertheless during the formation of the first primitive communities, commanders and leaders needed a place of rest, or wanted the entire hut to stand out somehow by specific placement or size, or some kind of sign above his plank-bed or entrance to his house.

Thousands of years before language, communication was achieved by primitive architectural symbols which had already shaped the environment and living space of the primitive man. In modern terms - a raw aesthetic symbolic language already existed.

With the development of the work tools and the growth of communities the buildings increased as well. Their architecture, together with more advanced constructive solutions became increasingly sophisticated and lush, the decor more detailed. The abundance of certain materials began to represent the class and power of individuals, which then moved on to representing the wealth and power of families, then clans, then cities and eventually entire countries and regions.

Together with evolution and development, and changing of empires, kingdoms and republics, slowly over the millenniums and centuries in the mode of replication had modified styles and principles of architecture.

And at the beginning of the last century, in 1917 after Marcel Duchamp exhibited his work "Fountain" which was in fact a typical porcelain urinal, this avant-garde conceptual art overwhelmed and still continues to influence the entire world of modern art, almost all traditional art rules and regulations had been broken or abandoned. At the same time the gateway to the unprecedented and unseen new world of unlimited possibilities in art and architecture had been opened. The free mind of the creator had been unleashed and the new idea that everyone can be an artist was introduced. At the time in the world of architecture, technical and engineering achievements strongly if not fundamentally changed the aesthetic orientations of architecture. Modernists like Adolf Loss, Giuseppe Terragni and especially Le Corbusier embraced and welcomed the new epoch of new aesthetics as an absolute liberation from any style or spiritual vagaries and eventually he proclaimed: style - it's a lie! The aesthetic of rationalism rejected any historical or traditional symbolism, and emotional expression. Paradoxically, even at those times architecture was not able to escape symbolism, new symbols of avant-garde architecture became maritime liners, airplanes, cars, and finally a very clear and direct idea of Corbu - "The house is a machine for living in" (Le Corbusier 1986: 96) became very true during this time.

Structures of glass and metal, rationalism and functionalism became acknowledged as a style after
Philip Johnson coined the term "International Style" at an architectural exhibition in New York, at the Museum of Modern Art in 1932. Refined, purified and elegantly simple geometry has become the new concept of beauty. Ludwig Mies van der Rohe's and Walter Gropius's ideas brought from Bauhaus blossomed in America and from there were exported back to Europe, but with a different name and in different quantities.

However this techno - euphoria, utopia soon ran out of steam. After the decades of semi - military strength and super - rational, anonymous architecture, architects and clients became heart sick for more expressive, more character oriented ideas, inspirations and meanings.

In 1945 Corbusier designed one of the most mysterious, symbolic and metaphor filled religious buildings of all time; The Notre Dame du Haute with its love, emotion and metaphor charged image had become a new symbol of modern architecture as a whole (Fig. 1).

Eero Saarinen's Trans World Flight Center at JFK was commissioned in 1956, the client wanted this building to capture the "spirit of flight", something vivid and emotionally evolved. Architecture is not only rationality, technology and economic efficiency; that is only one half of architecture. International style has ignored the other, perhaps more important emotional part of architecture for decades; the spiritual part of communication and sensuality. Time has proved that architecture has infinite space for an architect's self-expression and imagination, especially when it comes to the world of metaphors.

Frank Lloyd Wright's designed Guggenheim Museum opened in 1959 in New York City (Fig. 2). The process took 16 years to move from concept to realization, unfortunately neither the developer nor the architect were alive to see it open. His "inverted ziggurat,

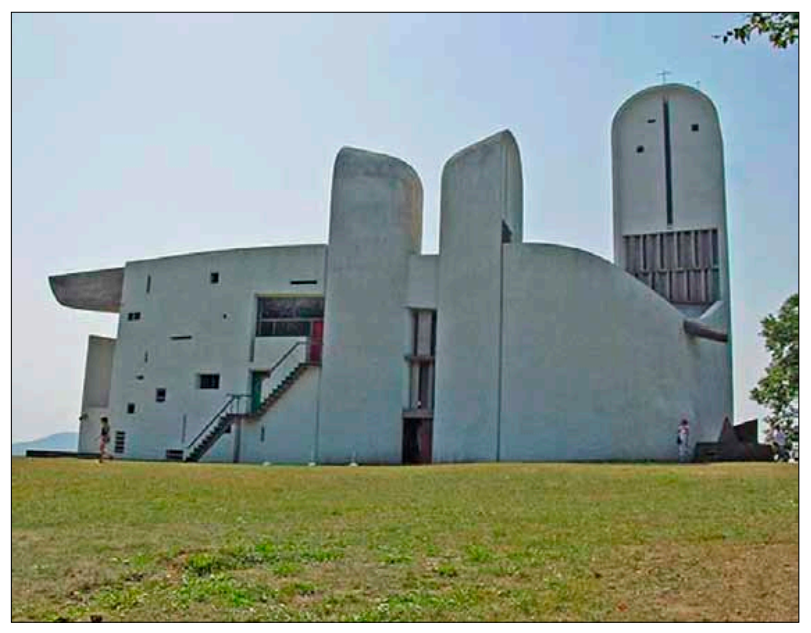

Fig. 1. The chapel of Notre Dame du Haut, Ronchamp 


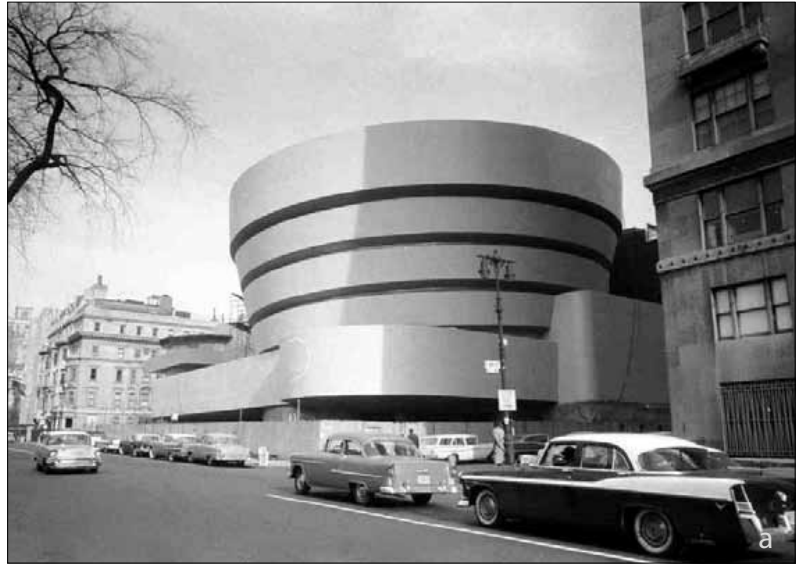

Fig. 2. Guggenheim Museum, New York

a stepped or winding pyramidal temple of Babylonian origin" (Drutt), was outstanding and extremely strange in the rigid and pale background of Fifth Avenue. Prior to the opening of the museum twenty-one artists signed a letter protesting the display of their work in such a space. Today the Guggenheim Museum became not only symbol of New York City, but also a symbol of modern art as we know it. Society responded in a similar way to a bold and brave creator's idea in Paris 60 years back in 1889 . Through strife, misery and ultimately his own personal investments engineer Gustave Eiffel's metal tower was build. Eventually the tower became one of the most famous and romantic symbols of the city and urbanism in all world.

The realization process of the Sydney Concert Hall was similarly shameful and offensive to that of Eiffel's. The architect was dismissed from the project halfway through construction and did not receive an invitation to the opening ceremony. Despite this however, the original idea survived and the concert hall stands as one of the most impressive building in the world today. Metaphor generously loaded, depending on the observer's mood and imagination, Jorn Utzon's Sydney concert hall has become a symbol not only of the city of Sydney, but became symbol of all country.

The city of Bilbao stepped into the global arena of modern culture with Frank Gehry's designed Guggenheim Museum, today the word Bilbao goes hand in hand with the word Guggenheim. Needless to say, this building has become a symbol not only of boldness and courage but also of possibility. It marked the starting point of the new three dimensional design era, it was an emotional and experiential desire which surpassed any expectations, it was a completely new language of three dimensional metaphors and unknown discoveries. Today, the three dimensional design became a routine tool. However new parametric modeling possibilities

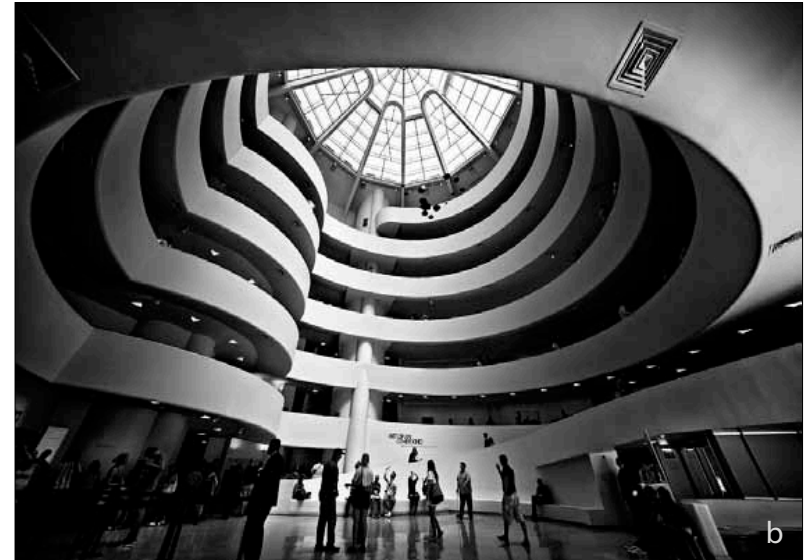

again immersed architecture into a new, more abstract world of forms and shapes. Nevertheless architects still use metaphors and symbols as the points of reference. We observe such a continuity in the works of not only world renowned architects like Zaha Hadid and Rem Koolhaas, but also in the works of the new generation rising stars like Bjarke Ingels, Ma Yansong and others.

Today, however we can say that there is an absolute creative freedom, pluralism, democracy, which is limited only by economics and common sense. Interestingly enough, architecture affects us in the same way as it did thousands of years ago; our emotional language of metaphors and symbols is more or less the same. Symbols became buildings, buildings became symbols.

The highest building or structure in any city becomes a symbol of that city. For example the medieval town San Gimignano in the central part of Italy is famous for its towers, the height of each tower is nothing more than a symbol of the self-esteem, power and influence of its owner or inhabitant, the function of this tower was just symbolic. Today the competition for the highest skyscraper is still on-going and on an international scale. With each wave of the economic boom here or there new symbols of unlimited political pride rise up to cosmic heights.

The Empire State Building, Chrysler Building and Petronas Towers are probably the most famous symbols of a city's skyline. The Chrysler Building because of its brave, expensive and expressive decor, pointing to the Chrysler car factory production became not only symbol of the city, but a symbol of all of New York in the pre-Depression era. There are plenty of more bizarre and amusing examples of singular buildings such as Jean Nouvel's Torre Agbar in Barcelona, representing something what was perhaps not the most beloved or desirable symbol for all citizens of the city, but it stands firmly on Barcelona's skyline to this day (Fig. 3). 


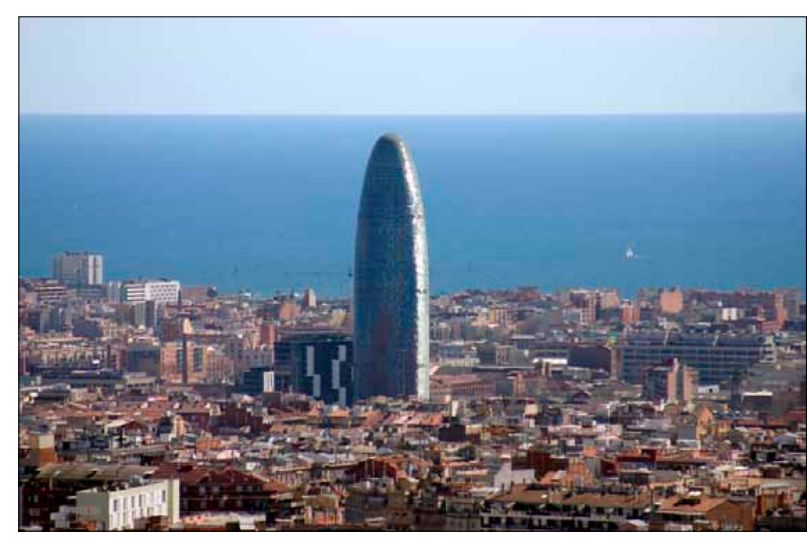

Fig. 3. Agbar Tower, Barcelona

A Symbol of the city may also be the most significant public building in the town such as a religious center, museum, concert hall, library, government palace, or airport.

To create a building that will eventually become the symbol of the city is by far the highest and most noble professional success for an architect. Obviously not everyone can be so fortunate with clients and not everyone is capable, it is not so simple to create a long lasting meaningful building. The consideration of not only physical, but also the emotional, social and historical context leading up to this point is essential.

When a building is a symbol, or a symbolic meaning of something, it begins to lose it 's material mass; it becomes timeless in its cyclical rebirth with reflection of the changing natural and urban context and each cycle resounding with its surrounding deeper and more meaningful. It becomes an enigmatic, metaphysical energy encoded and enriched with and by the times, with no letters, no notes and no sound. It encapsulates the value and genius of the creative mankind within itself. Cities would be very dull and dreary if architecture had confined itself to a singular geometry resounding only with the temporary aesthetics. How exposed and readable the information of symbols and metaphors are depends on the idea of creator, talent as well as the desire to say something, to share, or to conceal. Each building - is a kind of a statement, claim, or a declaration of fact, strength, joy, sadness, sometimes helplessness, boredom or in some cases disaster or even vanity. Architecture speaks through symbols - it seduces the eye with metaphors.

Not every architect's arsenal may or must contain a dictionary of symbols or metaphors since each architect as an independent creator has complete freedom. However, every architect should have "intrigue" in his quest for discovery and thought - our ideas about social problems, perhaps the solutions for global dangers, each going his own way observing the world from his eye level, and perspective of spiritual horizon.
The Chinese philosophy of Feng Shui, embraces the environmental harmonization and reflects a deep, spiritual and metaphysical knowledge of the world. Through experience and history we understand the invisible force which unites us to the earth and the earth to the universe. This bond is determined by elements outside of our physical sphere, the location of the stars, the changing of the seasons, and the more essential elementals; water and wind. This knowledge and mysticism of the east accumulated slowly through thousands of the years is a treasure of the eastern world's wisdom and lifestyle.

Today symbolism in architecture revives and actively gives meaning to the east, especially in China, where the wisdom of the past influences the solutions of the present in all aspects of daily life. Creative liberty, and volatile interpretation is acceptable and desirable in the economically flourishing China. The country's ambitions and limitless creativity of architects provoke more and more expansive and exciting works. Western architects working in China must learn the meanings of local symbols, because clients are acutely sensitive to any bold or visible swings in architecture, innocent looking abstractions to a Westerners eye are meaningful symbol to the Chinese. A KPF designed skyscraper seriously scared developers when they saw it as the "Japanese" rising sun over modern Shanghai. The architects had immediately replace the circular opening at the top of the high-rise with a rectangular one (Pedersen 2005).

\section{Metaphors and symbols in Fuksas architecture}

One of the most enigmatic figures in the world of modern architecture today is Massimiliano Fuksas working and living in Rome. His works are difficult to frame in any one style or direction and there is absolutely no need to do so. Each of his projects is different, but they all have the same dose of surprise and courage. Obviously sculptural and abstract, leading to ambiguous reflections while at the same time remaining laconic and highly individual. This is natural because Fuksas is first an artist, then an architect. Each project is a new interpretation of a typical legend of the building, like looking from a new unexpected point, or attempting to flip it upside down or invert the space, like a constant research for new notes, new sounds, new architectural dramas.

It's hard to say how closely an architect's mind orbits around the "constellation" of symbols and metaphors during the initial sketching process, however almost all of his works are emotionally loaded, his buildings stand as containers of energy and this energy is powerful enough to affect both external material and our in- 
ner emotional world. His works are often metaphors for our feelings; emotionally understandable but difficult to name. Abstract volumes and shapes and compositions are determined to gain their place in space and to become the dominant gravitational points of the area.

Massimiliano Fuksas is a practicing architect, his works and actions speak for themselves, he does not generate theories, he doesn't publish manifestos, he designs, builds and suggests his vision of architecture and urbanism. However Fuksas' written texts are a version of his own philosophy, his reflection and the ability to see things which are seemingly invisible. In the text of "Visible Invisible" we feel same sense of liberty that we do with all his architecture. His texts are not about architecture, but rather about history or the mood, the reasons of "what" and "why" first and maybe the "how" as second. He is interested in the phenomenon of urban chaos: its energy, "this energy which embodies urban chaos is somehow (though seemingly contradictory) organized and this disorganization yields confusion, it exists to such a point that each particle seems to run wild and then to regain its state of calm, to re-stimulate itself, to slow down speed up, and to stay still..." (Fuksas 1997: 111) It's not about architecture, it is "loser to the physics of magnetic fields than to simplified theory of classical town planning, or astrophysics, to fractals, or to non Euclidean geometry" (Fuksas 1997: 111).

Fuksas' architecture is not about examining architectural problems, for him it is infinitely more important to examine what comes after it, or what was "before" it. In this process, he avoids formality and breaks out of banal and conventional aesthetic limits. Fuksas' creative credo was very laconic spoken by words "Less Aesthetics, More Ethics" (Fuksas 2005: 170 ) at Architecture Biennial in Venice 2000, when he was appointed as a director. On the gigantic video screen - a wall of 280 meters long and 5 meters high, a nonstop direct translation of images from eleven world's biggest megacities were displayed which demonstrated the power of the virtual world and conscious metamorphic touch with reality, emotions and politics. The global phenomenon of megapolis, the role of architecture in the changing process of it, and the role of new media communication were the themes of the Biennial. Nominated two conceptually related ideas; as architect's connection with the media - the public service advertising, and use of a virtual images in the design process. Fuksas had no intentions of forging the way for the future or to create slogans of the era, however, he unlocked the door and left the questions open for reflections and discussions.

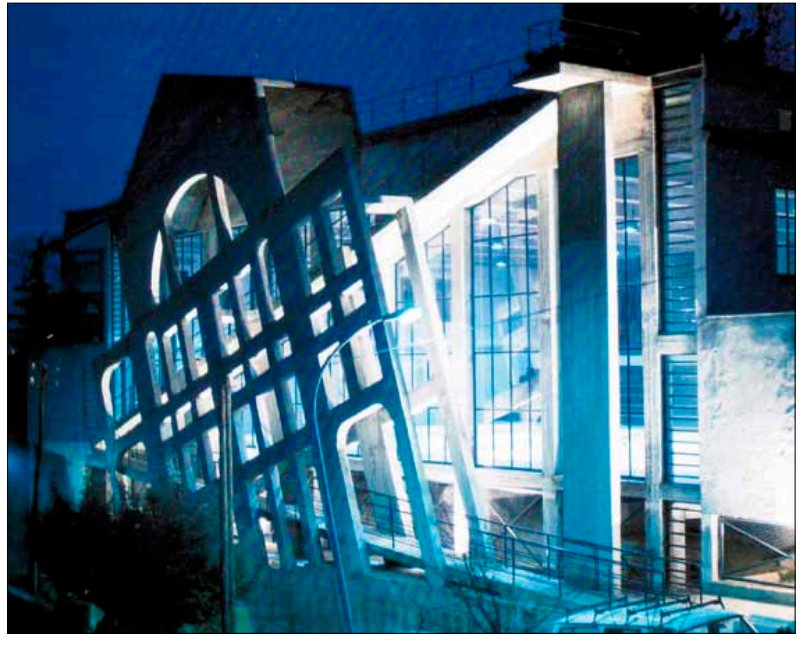

Fig. 4. Gym in Paliano, Frosinone

The first work of Fuksas to receive international recognition was a gym complex built in Paliano (Fig. 4), a small town near Rome. The tilted, pseudo historic facade on the slopes of a mountain catches one's eye from far away. Is it an outcome of earthquake or an architect's game, the interpretation of historical architecture in a city where history is missing? Or is it a signal to the society who are failing to protect the architectural heritage in Italy? Many ideas, a lot of guesswork, but there is no doubt the building has mesmerizing graphics and maximum expression. The entirety of this small town gained character. The anonymous, expressionless and vacuous view suddenly became dynamic, attractive and meaningful. The new, roughly poured concrete façade created a bold juxtaposition against the quiet town, but did not became a foreign body, did not overwhelm the feeling of the town, instead it made the town into something else, something cheerful and attractive. It was a symbiotic relationship.

Although not the biggest, but one of the most interesting works of Fuksas is the Nardini auditorium and presentation center of Bassano del Grappa Vicenza in Italy, constructed in 2004 (Fig. 5).

One of the oldest Italian grappa production company decided to build something interesting, unique and innovative for their 225 years anniversary celebration. The company's owner, Giuseppe Nardini, was looking for an architect who would be able to create a new identity for the company: a new symbol. Same time architect would be in charge of building more exposition and a meeting space for visitors, whose numbers at the time were greatly increasing. Fuksas' idea was to construct two glass bubbles resembling two grapes "floating" above the horizontal decorative pool. He sketched this idea on a plate during his first meeting 

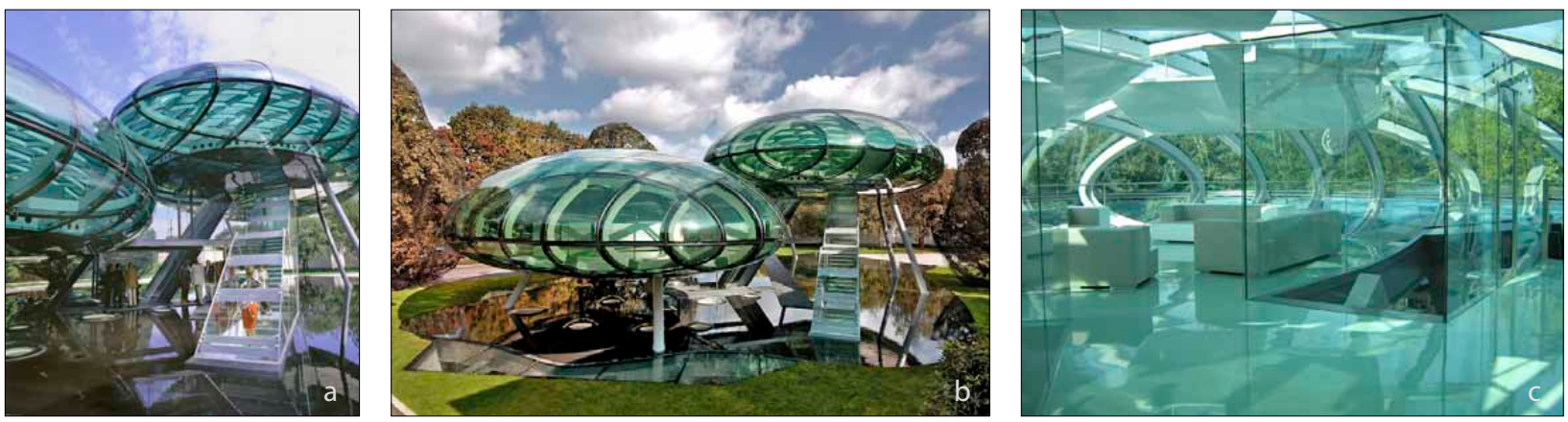

Fig. 5. Nardini Research Center and Auditorium, Bassano Del Grappa, Vicenza

with the client in a restaurant. This idea stuck and remained clear and untouched throughout the rest of the realization process.

Drawing delineated two organic volumes, two transparent drops of grappa or bubbles rising into the air which masterfully captured the idea of being lightweight and translucent, futuristic and suggestive. With Maximum transparency, reflections and play of light surrounded by its natural environment, this project can convince anyone that Nardini grappa is the best and most transparent grappa in the world. The movement within the complex reveals the manufacturing process of this famous drink, which begins in the earth, from the roots of the trees where the architect uses an authentic rough concrete and wood materials and colors with bright light slots like talking to us about full of mysticism world of the underground. From there by way of a glass staircase you ascend inside the masts of the green bubble, the "containers", where the sunlight and the diamond-shaped metal structure play with each other with a certain liveliness and enchantment that can make you just a little dizzy, the space suddenly becomes a virtual experience, like you are suddenly inside a futuristic ship about to sail away. Fuksas was able to create an emotional chain with his virtuoso manipulation of interior spaces, shapes, patterns and materials, this sense of respect expressive creativity takes us on a unique journey. At the same time the building is equally interesting from any point in the old park in the midst of which it stands. The initial idea of the two bubbles of grappa or vine drops is such a natural and undoubtable suggestion that anything else for the Nardini Exposition Center would be almost unimaginable. The architecture of the Nardini center is an excellent sample of well-balanced proportions of innovation, courage and metaphors which are subtle and not plainspoken. Two straight shapes are like two right words in poetry which describe the essence and our imagination starts its magic voyage.
So far the only project in New York City by Fuksas is the Armani flagship store in USA on Fifth Avenue (Fig. 6). The shop occupies four floors in addition to the basement space. All floors above street level are connected by staircase which shape is hard to describe in words, but seems like magnificent twister kind sculpture, structural spectacle, or can be called three dimensional installation. There is a crazy energy which seems to be frozen in the space, very elegant, but also savage and wild. An eye popping core and center of the especially extravagant Armani shop interior is yet another genuine creature of Fuksas.

During the design process the client had serious doubts: will one elevator be enough for all the visitors of the shop? Fuksas reassured the famous designer that he will design a staircase that will make all the patrons forget all about the elevator. And that's exactly what happened! Practically every visitor, no matter what age or size, climbed those stairs with a twinkle of enthusiasm and wonder in their eye as they ascended the free floating weightless staircase; admiring the changing perspective and the ethereal feeling of the fluttering white bands. That staircase is without a doubt the most powerful and essential element of the entire interior. It can be understood as a metaphor for the restless spirit of the creator, or the creative soul seeking space. All in all it is a dramatic, eye catching event in the space which charms and surprises all visitors. Seduced by the abundance of metaphors and image a whirlwind pulls us to the top, as if there we will find something more interesting and more amazing. And at the each upper level we enter quiet and dark spaces where tranquility and luxury prevail with the same calming power that they do in the mystical world of Armani. White as snow, the flexible stairs easily rise, continuously swinging, resembling easily free hand drawn lines (which they were at a certain point), and somewhat remind me of Frank Lloyd Wright's Guggenheim Museum. White color and small, but delicately precise stair detail with Art Deco flavor dispels any doubt that the Armani stairs have a 

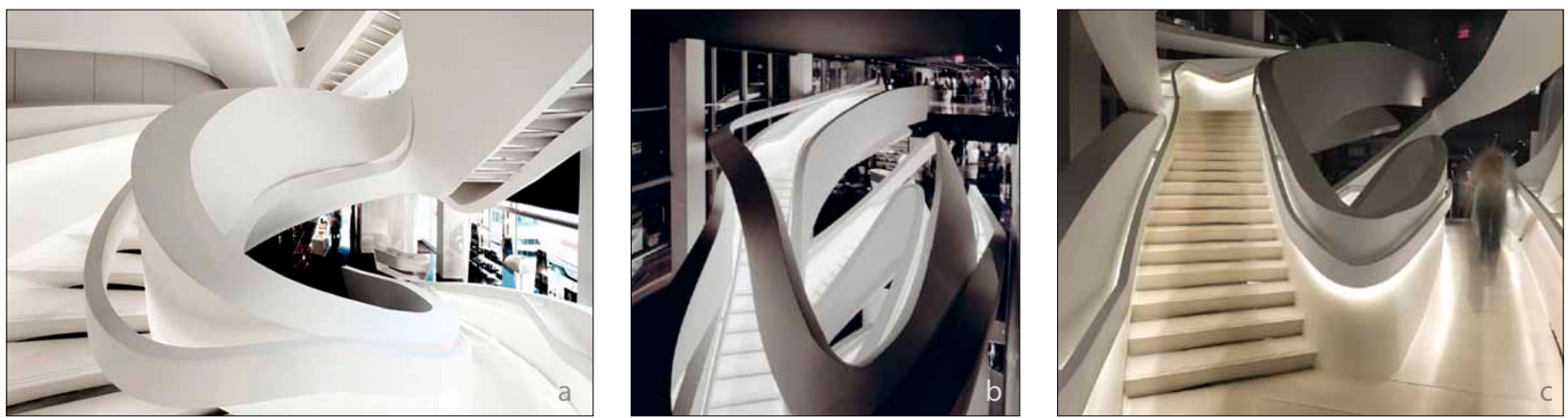

Fig. 6. Armani Store New York, 5th. Avenue

gentle, sensitive but also a direct connection with the world - the famous Museum and not any less famous Chrysler building linguistic and this encoded sign confirms in our subconscious, that what we see belongs to New York. It is bold and new, but at the same time it continues with the best of New York City's traditions. Once again, with the backdrop of dynamic and hipper expressive form it is concealed metaphor and symbol that speaks to us and appeals to our individual imagination, which like echo returns to prove, that what we see, is not a form, or shape or material, more important is what we feel and what lies behind all of it, the architect has created something new using best metaphor of modern New York City.

One of the smaller, but no less well known work of Fuksas is Entrance to the Museum of Prehistoric Graffiti Niaux in France (Fig. 7).

Resembling a giant sculpture or piece of earth art with a rusty metal surface take us on a journey into dark cave of the prehistoric past. As if a millions of years ago, a thin multi legged creature slither out of the stone cave for fresh air and overlook the splendor of Pyrenees valley and mountains. The obvious metaphor of something very primitive, antediluvian, extinct ten thousand years ago reinforces emotions in both directions impressive view looking to the breathtaking valley or moving in the direction of mystical cave,

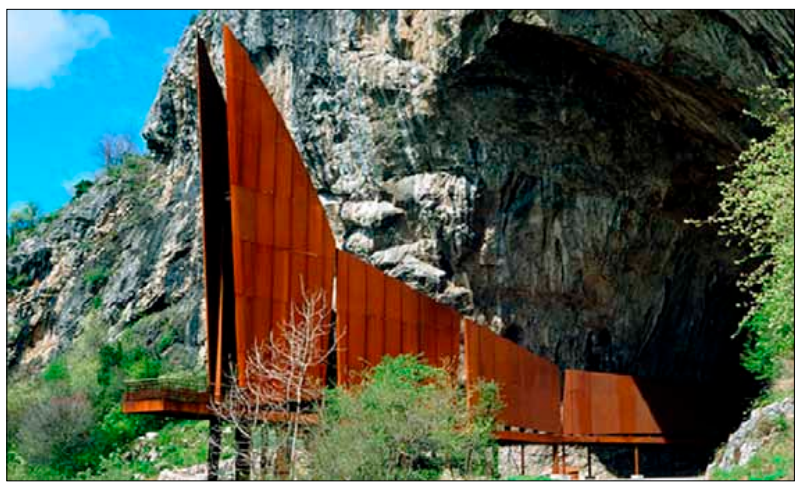

Fig. 7. The Cave Painting Museum in Niaux, France, entrance where thousands of years ago our ancestors lived and left a marks on the walls, never suspecting that it will become a world-renowned pieces of art. The majestic, heaven reaching planes leave no doubt that this mysterious ancient temple kind obscurity is a crossroad, a road between light and dark, is it an end or a beginning, or simple a junction of eternity?

The dramatic, expressive silhouette and bright brown, almost red natural "corten" colors organically pairing and adding to the valley's pallet of colors and ornaments of the rock's slowly and naturally layered and sandwiched by billions of years.

To this day the largest and coincidentally latest realized project by Fuksas is Shenzhen City International airport Terminal 3 in China (Fig. 8). The largest and first built terminal in the creative biography of the architect, has already been recognized as one of the most impressive new airports in the world by the cyber critics. Today no country in Europe nor in America would dare to implement such a complex and innovative building as Terminal 3 in Shenzhen International Airport. But the Chinese seem to have almost limitless resources, enormous ambitions and an ongoing economic prosperity which can provide unthinkable opportunities for architects and engineers to realize their most spectacular and unexpected creative ideas. Much like a Chinese puzzle the "skin" of the terminal is made up of more than a hundred thousand honeycomb shaped elements of different sizes; an unprecedented case in global building practice. The three dimensional pattern of glass and metal panels follows the continuously changing surface of the ellipsoid section, a more than one kilometer long oblong shaped main concourse, which smoothly transforms in all directions and eventually turns into a horizontal, freely waving semi-transparent plane overlaying the main departure hall. Or, viewed from the inside by a departing traveler's eye, the interior of main departing hall is broad and full of natural light, covered by the wavy, airy, three dimensional honeycomb ceiling structure. The entire 

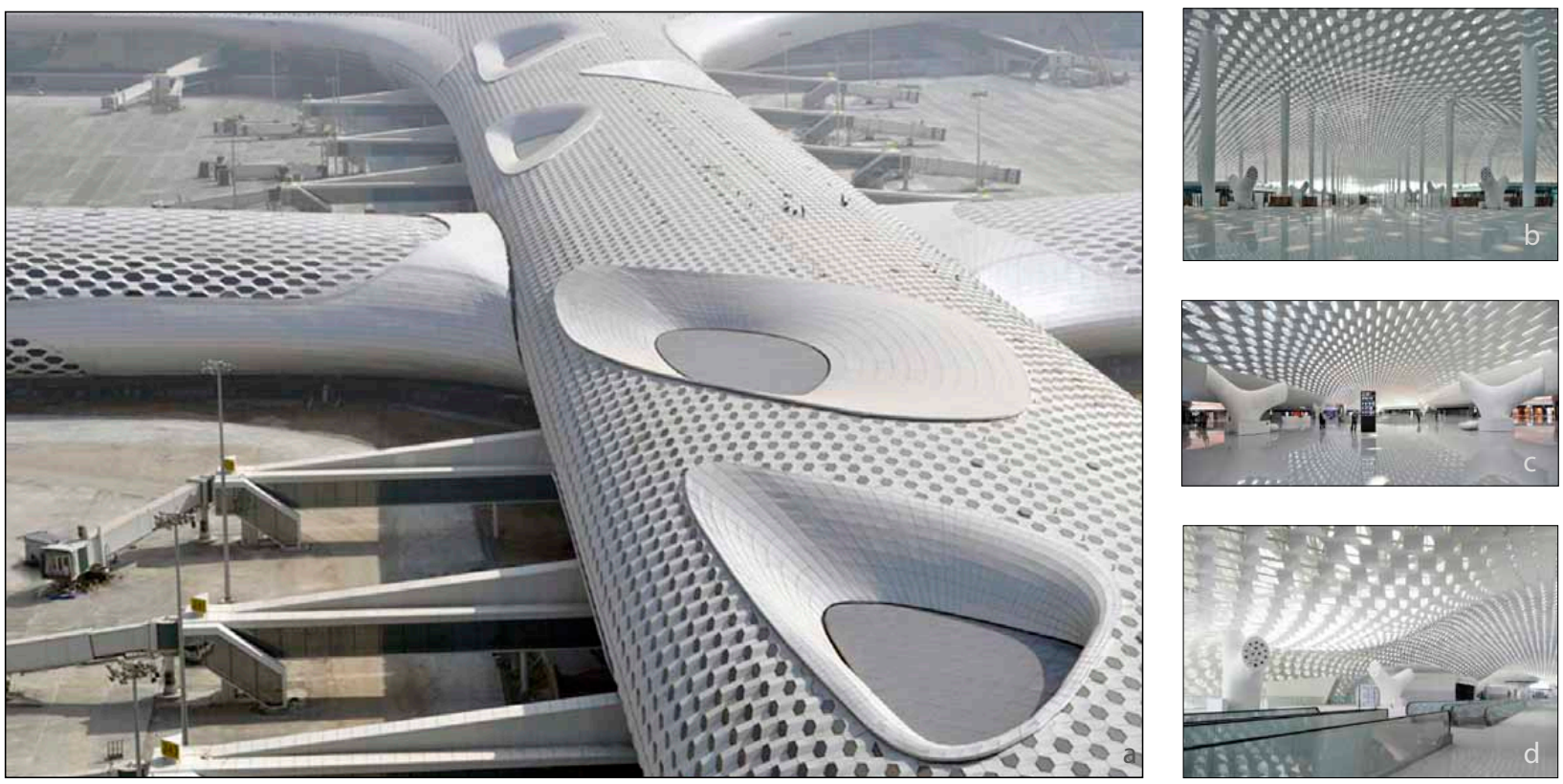

Fig. 8. Shenzhen Bao'an airport, Terminal 3

roof structure magically flickering, reflecting and filtering sunlight gradually narrowing and rolling forth into soft, seems endless moving perspective. This play with the space purposely directs and guides passengers towards waiting and boarding areas. The enveloping surface creates a mood and freedom of easy flight through an open space, like an unrestricted water surface, it loses any tangible feeling of the mass. The feeling of anticipated flight overwhelms the waiting halls; the amazing play of light and shade, delicate dynamics and unexpected reflections playfully create a unique and magical exhilarated mood, same as being in a temple or in a theatre when the light slowly dims and a silence settles in, in a few seconds the play will begin, the stage still empty, but everyone anticipates what will happen next and eagerly wait for the first motion, first sound, first light, first word. The forthcoming travel becomes something of an exciting event in itself, a small festivity, the entire space of the terminal is filled with a special feeling of holiday spirit and joy.

Inspiration and metaphor of a "Mantra ray fish that breathes and changes its own shape, undergoes variations, turns into a bird to celebrate emotions and fantasy of the flight" (Area 2013: 130).

The new terminal has already become the new symbol of the city of Shenzhen, it is a representation of both sides of China, the modern and the traditional, besides the chinese puzzle metaphor, a much stronger symbol is engraved in the honeycomb shaped skin; it symbolizes the skin of a dragon, a token on force and power in both ancient and present day China. The dragon, ruler of the air and water is the most recognized symbol in Chinese society. The predominantly white color both inside and outside also have a very important meaning within Chinese society, in addition white color represents righteousness, pureness, confidence, intuition, strength, ancestral spirits, courage vs sadness. The wishes of the client, and also the correct choices of metaphors and their meanings generate positive and accepting reactions from the public. New terminal arguably presents the model of modern China - the obvious symbol of limitless opportunities based on well interpreted past.

The "Cloud" as the main metaphor for new Congress Center appeared in the architect's vision during a flight from New York to Rome during the time when Fuksas was teaching at the Columbia University in New York. The architect envisioned great, undiscovered possibilities in the amorphous nature in this phenomenon.

"Nuvola" - the "Cloud" is Fuksas's largest project in Rome today (Fig. 9), the construction is still ongoing and the opening ceremony has been pushed forward many times. The city of Rome expects that the new Congress Centre will strengthen and modernize the image of the oldest metropolitan capital in Europe. This 58,000 square meter complex consists of the main auditorium space, two congress halls, the exhibition spaces, a hotel block and underground car parking. This project won against the five hundred other proposals in international competition held in 1998. The project while being distinctive and dramatic, still smoothly and correctly inserts into the urban landscape. EUR district in Rome one of the most successful urban projects of Italian rational- 

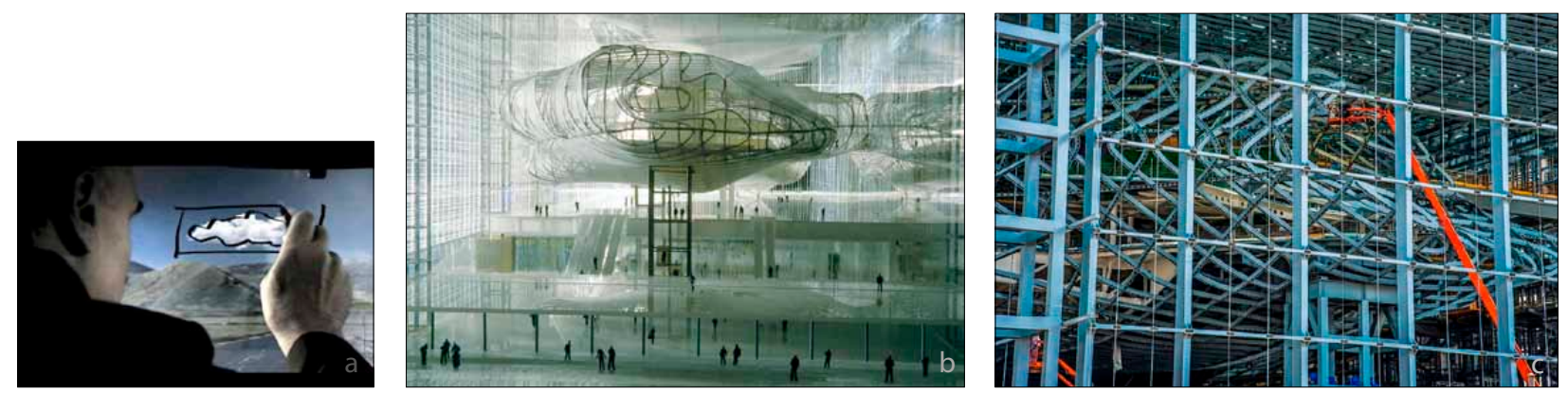

Fig. 9. "La Nuvola” Congress Palace in Rome

ism time. The powerful size of the plain rectangular glass box holds inside of it the freely accommodated, constantly changing form of the "Nuvola", which contains main auditorium. The volume of main auditorium hanging in the air will be covered by a semi - transparent high - tech fabric which filters and provides natural and artificial light during the day and night in and out and vice versa. The strange amorphous "cloud" will be further dematerialized and with its constant alteration, creates unique, intriguing artistic effects. This "cloud" could be seen as a sculpture, a performance of sorts but in the end it is a piece of architecture that contains a strong and unmistakable metaphor. The Congress complex filled with an ephemeral intelligence, filled with ideas, discussions and a whirlwind of though can, as a cloud may, suddenly turn into a natural disaster, a threatening tornado or it can be a cloud without rain or power, floating calmly without seeming purpose and then disappearing without a trace. The mystifying power and peace of thought.

It looks shapeless at first, but it has it's own unique and authentic form and impressively hangs over the solid floor surfaces of Congress Centre. It looks free, but at the same time it is closed, encased, and yet a self - changing body able to adapt to the given environment. Exterior geometry looks clear and rigorous and yet like the human souls it internally twists and turns and becomes a complicated, incomprehensible net, it's hard to believe that all of it is made of heavy metal and weights hundreds if not thousands of tons. The flexibility and the play of lines appears so easy and graceful, that somewhat resembling Italian spaghetti and all construction site does look like the famous gourmet Italian cuisine kitchen, with a lot of noise and all kinds of flavors, shimmering birth of something special that City of the Rome being so hungry for and waiting 16 years.

Back to Le Corbusier's words about the architect's work we obviously see a strong spiritual and emotional grounds as a necessity based on simple and basic hu- man feelings and understanding of creative beauty. No charts, surveys, and other kinds of anachronistic, unnecessary analysis can create fully-fledged architecture, this is accomplished not by pedantic precision of calculation. Only the unknown, boundless world of imagination, ability to create, manipulate our emotions by three dimensional material images and through the senses we truly experience. It is not so important how it is built, the value which never goes on sale is what architecture contains within, what is hidden and dormant, not the material world, but what kind of emotions and signs are encrypted in it and what kind of energy the building generates. Periodical reincarnation of symbols is not directly visible, but the apparent symbols and metaphors and allusions to them is a main communicative value of architecture. Symbols and metaphors which reflect in our personal sub-consciousness build up connections with the environment and mass of material, history and time and human intelligence with the world.

This is exactly what we see and feel observing Fuksas' works, his buildings are not only extravagant, innovative and outstanding, the essential value and merit of Fuksas architecture lies in their ability to become symbols of the place, they generates new energy with a new metaphor, new integral link, new functioning architectural body with his own legend and value.

\section{Conclusions}

1. The most expressive and innovative architectural projects are most likely initially rejected by the society of the era, but eventually they can become a new symbol.

2. Contemporary architecture is full of symbols and metaphors, although not necessarily emphasizing them.

3. Individual accepts and adopts metaphors and symbols depending on his or her subconscious creative potentiality, the openness of their mind and personal education. 
4. The Architecture of Fuksas represents the expressive and dynamic way of communication, almost every object has several metaphorical meanings.

5. Fuksas buildings are vibrant and full of energy, his architecture becomes an iconic point of attraction. Charismatic architecture as a charismatic personality has the ability to change the status and mood of the place.

\section{References}

Le Corbusier. 1986. Towards a new architecture. New York: Dover Publications, INC.

Drutt, M. (Ed.). Text at Guggenheim Museum, New York.

Pedersen, W. 2005. Lecture at Columbia University, 2005, New York.

Fuksas, M. 1997. One.Zero Architecture. Diagonale s. r. l. Roma.

Fuksas, M. 2005. Opere e progetti 1970-2005. Milanop: Skira editore.

Area. 2013. Rivista di architettura. Matta Architettura. DCB Bolognia.

\section{SAULIUS GECAS}

Studio WOA (workshop of open architecture), Via Ancona N. 21 sc.A, int. 10, C.A.P. 00198 Rome, Italy.

E-mail: sauliusgecas@hotmail.com

Saulius Gecas is a practicing architect who graduated from Vilnius Academy of Fine Arts and worked in Lithuania and USA. He is an author of numerous architectural projects. Currently he works as an architect in Italy, founder - partner of architectural studio WOA in Rome. 